\title{
ENHANCED NATURAL BIODEGRADATION OF DIESEL FUEL CONTAMINANTS IN SOIL BY ADDITION OF WHEY AND NUTRIENTS
}

\author{
Ana Paola Vilches ${ }^{a}$ \\ Dan Bylund ${ }^{a}$ \\ Anders Jonsson ${ }^{b}$ \\ ${ }^{a}$ Department of Natural Sciences, Engineering and Mathematics, \\ Mid Sweden University, Sweden \\ ${ }^{b}$ Department of Engineering and Sustainable Development, \\ Mid Sweden University, Sweden
}

\begin{abstract}
The contamination of soils by petroleum hydrocarbons, such as diesel fuel, has since many years been a serious environmental problem. Treatment of contaminated areas is a concern for governments and environmental authorities in several countries and efforts have been done with the purpose to eliminate this problem. Different methods have been tested and today the most common technique involves the excavation and transportation of contaminated soil to special treatment facilities. In earlier studies we have demonstrated the effect of adding organic amendments, such as fermented whey, on the biodegradation of $n$-alkanes in diesel contaminated soil. Non-fermented sweet whey also proved significantly to enhance the biodegradation of an aromatic substance (phenanthrene) in contaminated soil.

The current paper presents the results of an in-situ field test at a former gas station in the north of Sweden. In parallel to the field study, biodegradation profiles were monitored under controlled laboratory conditions by taking soil samples from the contaminated site and spike them with diesel fuel. The experiments were carried out by adding whey and mineral nutrients (NPK) to the test area and to the laboratory samples, and monitor the degradation of hydrocarbons by gas chromatographic analysis of extracted soil samples. Significant effects on the degradation rates were achieved in the laboratory tests. For the in-situ test, however, no such positive effects could be registered.
\end{abstract}

\section{KEYWORDS}

Biodegradation; Diesel fuel; Milk whey

https://doi.org/10.15626/Eco-Tech.2010.105 


\section{INTRODUCTION}

Treatment of diesel contaminated soil has been an important issue since many years. Many methods have been tested and today the most common practices include the excavation of large amounts of soil and the transport of the contaminated soil to specialized treatment plants which are sometimes located at great distance from the contaminated site. Results from a screening life cycle assessment indicates that road transport of contaminated soil has a significant environmental impact compared to in-situ treatment of the contaminated site [1]. Methods for both in-situ and ex-situ treatment include addition of food waste, addition of surfactants, aeration, biodegradation in reactors etc. [2-5], and biodegradation by bacteria immobilized onto hybrid support [6]. The stimulation of microbiological degradation can also be enhanced by the addition of easy degradable carbon sources. In earlier studies we have demonstrated the effect of adding organic amendments, such as fermented whey, on the biodegradation of $n$-alkanes in diesel contaminated soil [7-9]. Non-fermented sweet whey also proved to significantly enhance the biodegradation of an aromatic substance (phenanthrene) in contaminated soil (unpublished results).

Milk whey is a by-product of the dairy industry, and causes great disposal problem because of the large amounts produced. In the current study, the effects of adding whey in combination with mineral nutrients (NPK) to a diesel contaminated site were investigated. Additional tests were carried out at the laboratory to monitor the degradation profile in soil under more controlled conditions.

\section{EXPERIMENTAL}

\subsection{In-situ field experiment}

The field experiment was carried out at a diesel contaminated site in Gäddede, northwestern Sweden $\left(65^{\circ} 30^{\prime} \mathrm{N}, 14^{\circ} 09^{\prime} \mathrm{E}\right)$. A prior investigation of the site carried out by Sweco Environmental AB in 2008 was used as a reference. This investigation pointed out an area with relatively high loads of C12-C35 (Table 1), which was selected for the in-situ treatment. A $1 \mathrm{~m}^{2}$ area was enclosed and treated with an initial dose of $545 \mathrm{~g}$ NPK fertilizer (Hammenhögs väx upp, $18 \% \mathrm{~N} ; 4 \% \mathrm{P} ; 10 \% \mathrm{~K}$ ) followed by bi-weekly doses of $3.2 \mathrm{~L}$ milk whey.

\subsection{Laboratory experiments}

The soil used in the laboratory tests had a $\mathrm{pH}$ of 7.2 and a water holding capacity of $0.26 \mathrm{~g} / \mathrm{g}$. Soil collected nearby the diesel contaminated site was sieved and homogenized, where after two laboratory tests were set up. In laboratory test A (Table 2), 12 microcosms with $900 \mathrm{~g}$ soil were prepared in glass vessels covered with aluminum foil. NPK fertilizer $(0.7 \mathrm{~g} / \mathrm{kg})$ was added to all microcosms, and half of them artificially contaminated with diesel fuel at a concentration of $3520 \mathrm{mg} / \mathrm{kg}$. Then half of the controls and half of the diesel contaminated microcosms were bi-weekly treated with milk whey at a dose of $3.7 \mathrm{~mL}$. In conjunction with the whey treatment, all the microcosms were tumbled and random samples of $5 \mathrm{~g}$ soil were taken.

In laboratory test B, 3 additional microcosms were set-up according to Table 3 in order to study the effect of milk whey alone at different dosages. All microcosms were kept at a constant temperature around $22^{\circ} \mathrm{C}$ during the course of the experiments. 


\subsection{Chemical analysis}

For the field experiment, the soil temperature was measured at each treatment occasion. At the end of the study, soil samples from $0-0.5 \mathrm{~m}$ depth were taken with a soil core drill and sent to ALS Scandinavia AB (accredited commercial laboratory) for extraction with accelerated solvent extraction (ASE) and quantitative analysis by gas chromatography-mass spectrometry (GC-MS).

The soil samples taken from the laboratory tests were extracted by ASE, using a DIONEX 200 instrument. From each sample, an amount of approximately $4 \mathrm{~g}$ soil was mixed with dispersant agent pelletized diatomaceous earth (DE) in a proportion of 4:1 sample/DE. A disposable cellulose filter was inserted at the bottom of every the cell before transferring the sample quantitatively. Before closing the extraction cell a measured amount of hexamethylbenzene (HMB) was added as an internal standard (IS). Static extraction was performed with $100 \%$ pentane at 1500 psi and $120^{\circ} \mathrm{C}$ for 5 minutes.

The extracts were then subject to GC analysis on a Varian GC 3400 instrument equipped with a flame ionization detector (FID). An EC-1 column $(30 \mathrm{~m} \times 0.32 \mathrm{~mm}, 0.25 \mu \mathrm{m})$ was used with temperature gradient ranging from $50 \mathrm{C}$ to $280^{\circ} \mathrm{C}$ in $45 \mathrm{~min}$. Peak areas relative to HMB was used for quantification in order to monitor the breakdown profiles. Complimentary analyses were run on a GC-MS instrument (Trace MS, Thermo Finnigan) in order to verify the identity of the registered peaks.

Table 1. Results of chemical analysis of soil from the field study site at 0.0-0.5 m depth. Concentrations are given in $\mathrm{mg} / \mathrm{kg} d w$ soil. Values above guideline values are marked in bold font.

\begin{tabular}{lccc}
\hline \multicolumn{1}{c}{ Substance } & $\begin{array}{c}\text { Before } \\
\text { treatment }\end{array}$ & After treatment & $\begin{array}{c}\text { Guideline values (less } \\
\text { sensitive land use)* }\end{array}$ \\
\hline Aliphatic $>$ C5-C8 & $<10$ & $<10$ & 80 \\
Aliphatic $>$ C8-C10 & $<10$ & 32 & 120 \\
Aliphatic $>$ C10-C12 & 159 & 160 & 500 \\
Aliphatic $>$ C12-C16 & $\mathbf{1 2 0 0}$ & $\mathbf{1 2 0 0}$ & 500 \\
Aliphatic $>$ C5-C16 & $\mathbf{1 4 0 0}$ & $\mathbf{1 4 0 0}$ & 500 \\
Aliphatic $>$ C16-C35 & 850 & 750 & 1000 \\
Aromatic $>$ C8-C10 & 44 & 22 & 50 \\
Aromatic $>$ C10-C35 & $\mathbf{6 7}$ & $\mathbf{9 5}$ & $15 / 30$ \\
Benzene & $<0.01$ & $<0.01$ & 0.04 \\
Toluene & $<0.05$ & $<0.05$ & 40 \\
Ethylbenzene & $<0.05$ & $<0.05$ & 50 \\
Xylene & $<0.05$ & $<0.05$ & 50 \\
PAH, low MW & 0.17 & 0.41 & 15 \\
PAH, middle MW & 1.2 & 0.74 & 20 \\
PAH, high MW & $<0.32$ & $<0.3$ & 10 \\
\hline
\end{tabular}

*Swedish EPA 2009 [10] 
Table 2. Experimental design for laboratory test $A$.

\begin{tabular}{ccc}
\hline Microcosm ID & Spiking with diesel & Bi-weekly treatment with whey \\
\hline 1 & + & + \\
2 & + & + \\
3 & + & + \\
\hline 4 & + & - \\
5 & + & - \\
6 & + & - \\
\hline 10 & - & + \\
11 & - & + \\
12 & - & + \\
\hline 13 & - & - \\
14 & - & - \\
15 & - & - \\
\hline
\end{tabular}

Table 3. Experimental design for laboratory test $B$.

\begin{tabular}{cccccc}
\hline $\begin{array}{c}\text { Microcosm } \\
\text { ID }\end{array}$ & $\begin{array}{c}\text { Amount } \\
\text { of soil } \\
(\mathrm{g})\end{array}$ & $\begin{array}{c}\text { Diesel } \\
\text { addition } \\
(\mathrm{ml})\end{array}$ & $\begin{array}{c}\text { Diesel } \\
\text { concentration } \\
(\mathrm{mg} / \mathrm{kg} \mathrm{dw} \text { soil })\end{array}$ & Treatment & $\begin{array}{c}\text { Whey } \\
\text { addition } \\
(\mu \mathrm{L})\end{array}$ \\
\hline 1B & 225 & 1.0 & 3238 & No & 0 \\
2B & 100 & 0.5 & 3642 & $\mathrm{X} \mathrm{4}$ & 1700 \\
3B & 100 & 0.5 & 3654 & $\mathrm{X} \mathrm{1}$ & 425 \\
\hline
\end{tabular}

\section{RESULTS}

\subsection{In-situ field experiment}

At each whey treatment occasion, the soil temperature was measured at the field experimental site (Figure 1). The results from the GC-MS analyses are given in Table 1, and as can be seen, no effects from the treatment were registered for the contaminants.

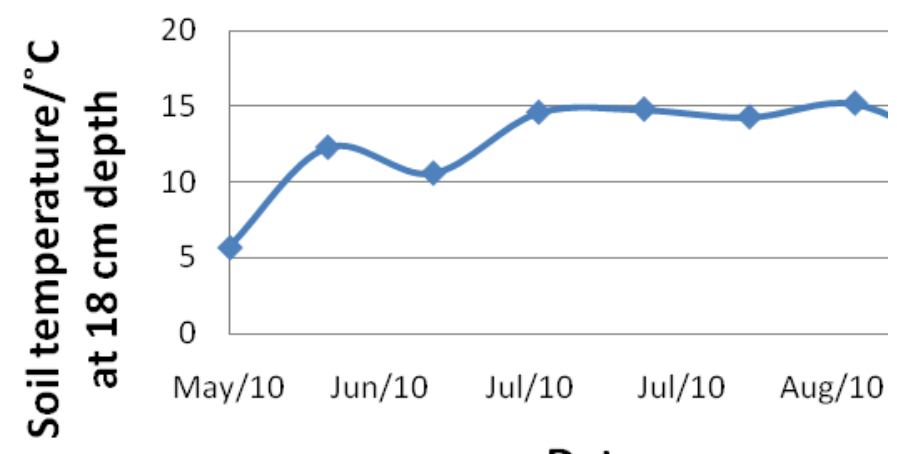

\section{Date}

Figure 1. Soil temperature profile at $18 \mathrm{~cm}$ depth during the in-situ experiment. 


\subsection{Laboratory experiments}

A typical chromatogram with the n-alkanes, the internal standard and some diesel additives marked is shown in Figure 2. The results from the two laboratory tests are summarized in Figure 3, displaying the degradation over time for the n-alkanes in the ranges $\mathrm{C} 11-\mathrm{C} 16$ and C17-C21. For laboratory test B, also the degradation of two diesel additives in terms of methyl esters of fatty acids were monitored (Figure 4).

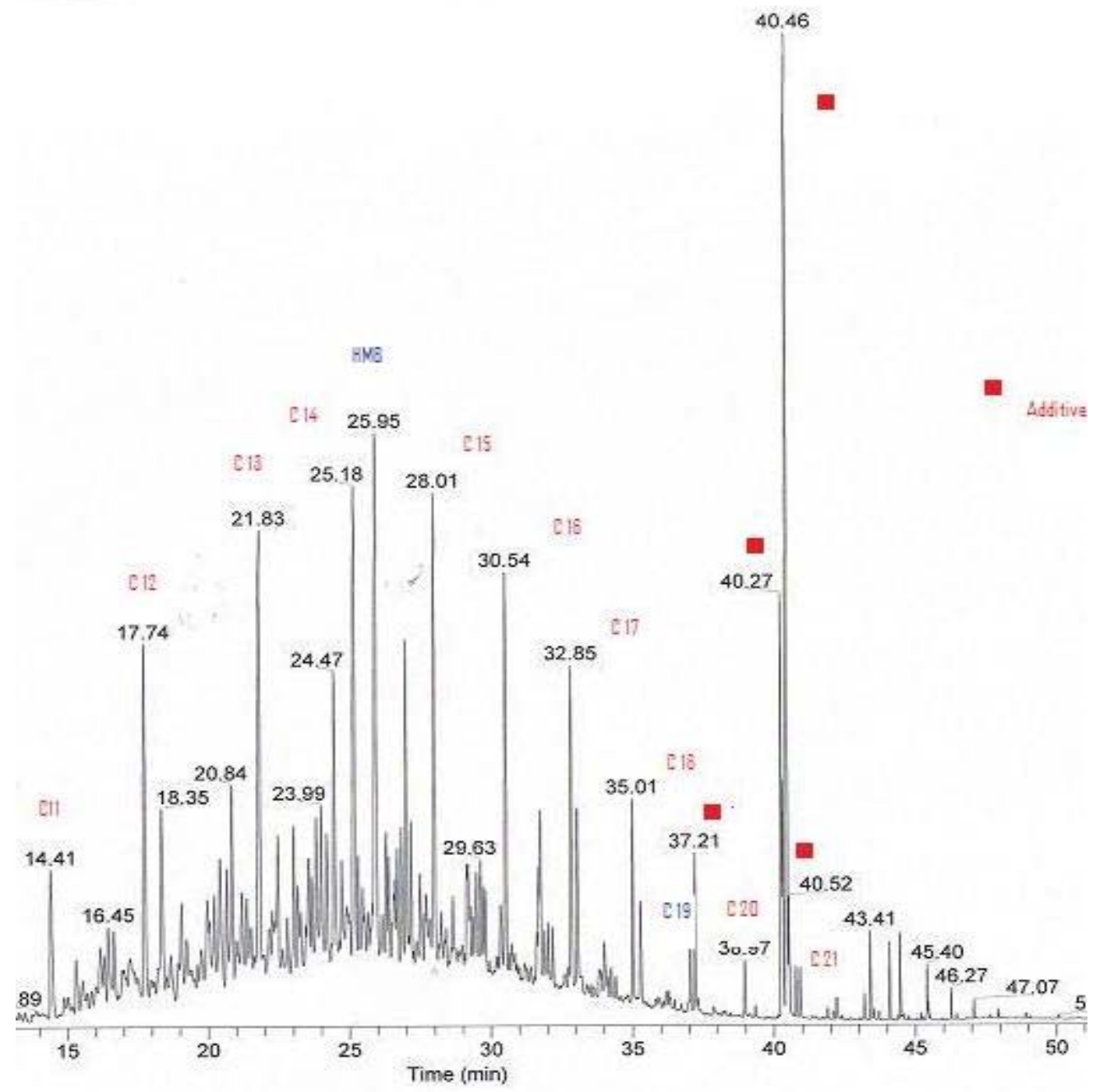

Figure 2. GC-FID chromatogram of diesel pollutants in a soil extract. The labeled peaks correspond to n-alkanes, diesel additives, and the internal standard HMB. 
Linnaeus ECO-TECH '10

Kalmar, Sweden, November 22-24, 2010
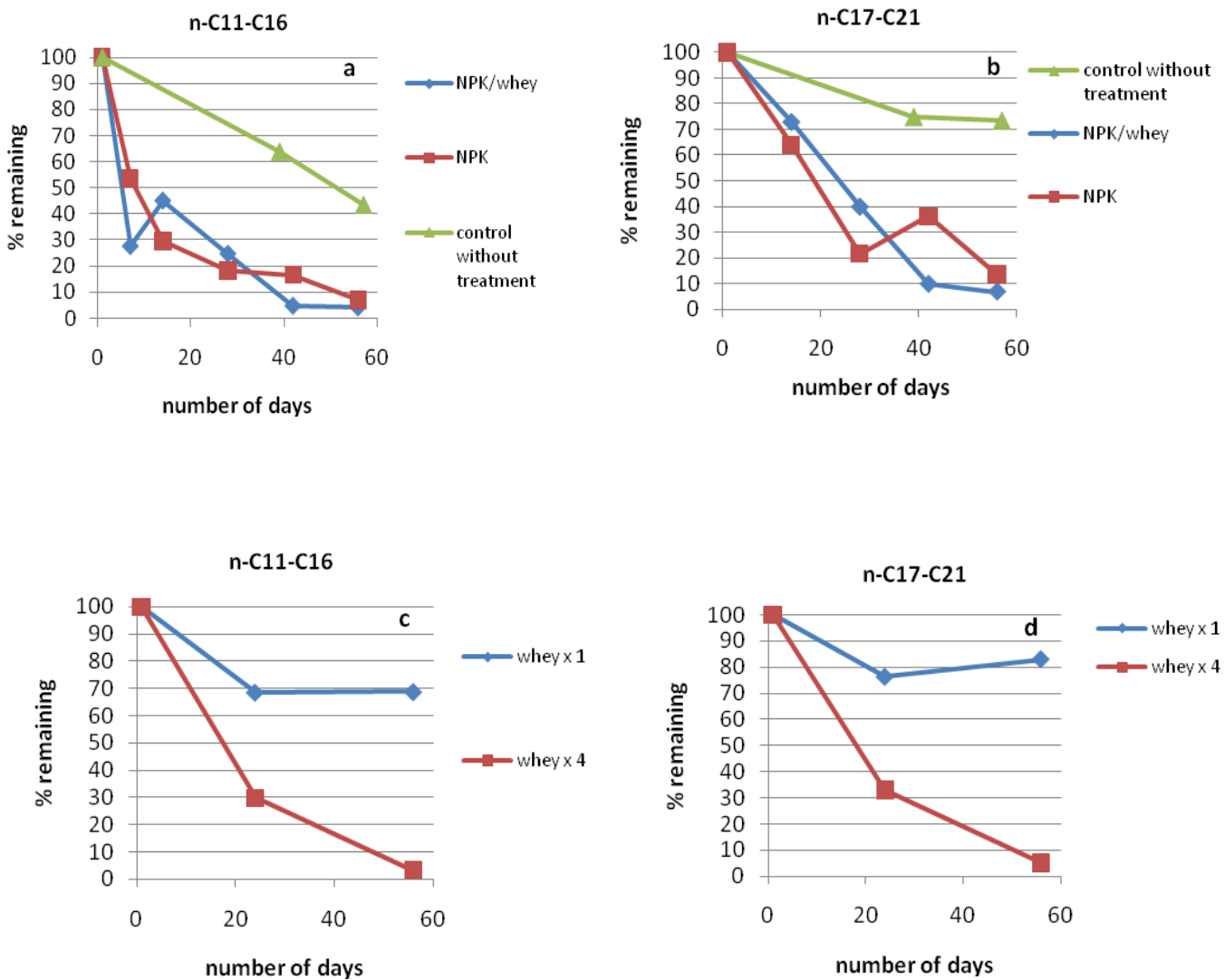

Figure 3. Breakdown of the diesel pollutants. a) n-C11-C16 fraction under the effect of different treatments. b) n-C17-C21 fraction under the effect of different treatments. c) Effect of milk whey dose on the n-C11-C16 fraction. d) Effect of milk whey dose on the n-C17-C21 fraction.

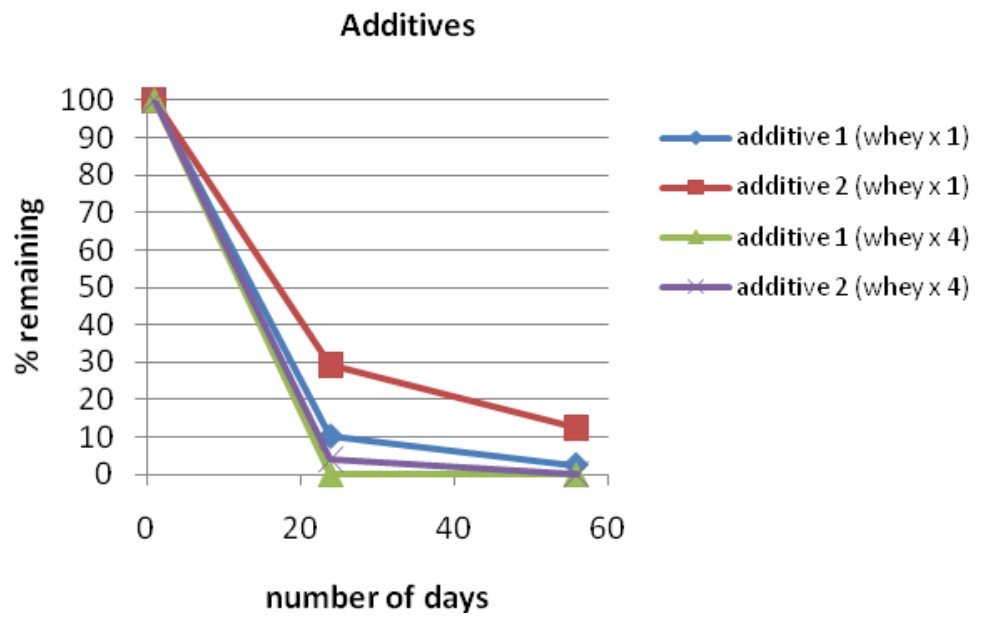

Figure 4. Effect of milk whey treatment on the degradation of ester type diesel additives. 


\section{DISCUSSION}

Accordingly to test A an accelerated breakdown of diesel contaminants is seen when NPK amendment in a concentration of $0.7 \mathrm{~g} / \mathrm{kg}$ dw soil is used. The total amount of the $\mathrm{n}-\mathrm{C} 11-\mathrm{C} 16$ portion is reduced by $90 \%$ after 56 days. During the same period the non treated control showed a $58 \%$ reduction, see Figure $3 a$. Accordingly to test A the n-C17-C21 portion also shows a breakdown of similar magnitude with a reduction of $85 \%$ compared to a control that shows a reduction of only $30 \%$, see Figure $3 b$.

When NPK amendment is used together with whey in the concentration of $253 \mathrm{mg} \mathrm{dw} / \mathrm{kg} \mathrm{dw}$ soil the reduction is up to $95 \%$ in the case of the $\mathrm{n}-\mathrm{C} 11-\mathrm{C} 16$ portion and $90 \%$ in the case of the n-C17-C21 portion, see Figures $3 a$ and $3 b$, respectively.

The standard addition of whey ( $253 \mathrm{mg} \mathrm{dw} / \mathrm{kg} \mathrm{dw}$ soil) used in test A in this investigation was based on our earlier experience from experiments from with fermented whey [7-9]. By comparing the results in Figure 3 it is obvious that this was not the optimal whey dose. In fact whey alone at this dosage does not increase the degradation rate compared to the control. On the other hand, test B demonstrates that a four times higher dose of whey significantly affects the degradation rate of the contaminants, see Figures $3 c$ and $3 d$.

Accordingly to test B, after 24 days the use of whey in a concentration of $1012 \mathrm{mg} \mathrm{dw} / \mathrm{kg} \mathrm{dw}$ soil gives a reduction of the n-C11-C16 portion of $70 \%$ in compare to the standard concentration which shows a reduction of only 30\%, see Figure $3 c$. After 56 days the difference was even bigger with values of $30 \%$ and almost $100 \%$ respectively. For the nC17-C21 fraction, similar results are observed, see Figure 3d. Also for modern diesel additives, the high whey dose seems efficient (Figure 4).

The results of the in-situ test were not as promising (Table 1). The values are in fact the same as before the treatment. There can be several reasons for the apparent resistance to degradation during the $31 / 2$ months of the field experiment. The most plausible causes for lack of response to treatment are (without priority order) low soil temperature, whey dose, whey availability and time. Figure 1 shows the soil temperature profile at $18 \mathrm{~cm}$ depth during the course of the field experiment. The figure shows a very low surface soil temperature during the summer months, which is rather typical for these northern latitudes. Hence, lack of observed degradation may be due to the low temperature in combination with short treatment time.

In the in-situ experiment the amendments were added to the surface. The whey being very fluid is expected to percolate through the soil helping the mineral nutrients to penetrate the soil as well. Drill samples of the soil indicated occurrence of clay soil in the deeper layer (2-5 $\mathrm{dm}$ ). This may substantially affect the ability of whey to percolate through the soil and thus the availability of whey to parts of the polluted soil may have been limited. In the presence of these issues the time is a crucial factor, the experiment was carried out during 16 weeks. It looks like under the present conditions in the north of Sweden is necessary to follow up an insitu experiment for longer time. Furthermore experiments should be carried out with the aim of determining optimal dose and way of administration of the amendment. 


\section{CONCLUSIONS}

This study demonstrates that the addition of amendments such as whey and NPK has a significant effect on the breakdown of diesel pollutants in soil when the conditions are favorable for this. Treatment time, soil temperature, amendment concentration and availability to soil pollutants are crucial factors that should be considered in further in-situ method development.

\section{ACKNOWLEDGEMENTS}

We are indebted to Sweco Environment $\mathrm{AB}$ for supporting the project and for use of soil sampling equipment. We also thank Milko $\mathrm{AB}$ in Östersund for providing the whey used in this study, and SCA R\&D, Sundsvall, for providing equipment for ASE and GC-MS analysis.

\section{REFERENCES}

[1] Tajam, J.A., Jonsson A.P., Fröling, M., 2010. Small scale in-situ bioremediation of diesel contaminated soil - screening life cycle assessment of environmental performance. Proceedings of Linnaeus ECO-TECH '10, November 22-24. 2010, Kalmar, Sweden.

[2] Joo H.S., Phae C.G., 2007. Degradation of diesel oil in soil using food waste composting process. Biodegradation 18, 597-605.

[3] Whang L-M, Liu P.W, Ma C.C., Cheng S.-S., 2009. Application of rhamnolipid and surfactin for enhanced diesel biodegradation- Effects of $\mathrm{pH}$ and ammonium addition. Journal of Hazardous Materials 164, 1045-1050.

[4] Vieira P.A., Vieira R.B., Faria S., Ribeiro E.J., Cardoso V.L., 2009. Biodegradation of diesel oil and gasoline contaminated effluent employing intermittent aeration. Journal of Hazardous Materials 168, 1366-1372.

[5] Nikakhtari H., Song W., Kumar P., Nemati M., Hill G.A., 2010. Scale up of diesel biodegradation in a beffled roller bioreactor. Chemosphere 79, 1010-1016.

[6] Lee Y.C., Shin H.J., Ahn Y., Shin M.C., Lee M., Yang J.W., 2010. Biodegradation of diesel by mixed bacteria immobilized onto a hybrid support of peat moss and additives: A batch experiment. Journal of Hazardous Materials 183, 940-944.

[7] Östberg T.L., Jonsson A.P., Lundström U.S., 2006. Accelerated biodegradation of nalkanes in aqueous solution by the addition of fermented whey. Internal Biodeterioration and Biodegradation 57, 190-194.

[8] Östberg, T.L., Jonsson, A.P., Bylund, D., Lundström, U.S., 2007. The effects of carbon sources and micronutrients in fermented whey on the biodegradation of n-hexadecane in diesel fuel contaminated soil. International Biodeterioration and Biodegradation 60, 334-341. [9] Östberg, T.L., Jonsson, A.P., Lundström, U.S., 2007. Enhanced degradation of nhexadecane in diesel fuel contaminated soil by the addition of fermented whey. Soil and Sediment Contamination 16, 221-232.

[10] Swedish EPA (2009) Guidelines for contaminated soil. Report 5976. 